\title{
Critical role of gap junction communication, calcium and nitric oxide signaling in bystander responses to focal photodynamic injury
}

\author{
Bianca Calì ${ }^{1,2}$, Stefano Ceolin³ ${ }^{3}$ Federico Ceriani ${ }^{1,3}$, Mario Bortolozzi ${ }^{1,3}$, Andrielly \\ H.R. Agnellini ${ }^{1,2}$, Veronica Zorzi ${ }^{1,3}$, Andrea Predonzani ${ }^{4}$, Vincenzo Bronte ${ }^{1,5}$, Barbara \\ Molon $^{4, *}$ and Fabio Mammano ${ }^{1,3,6, *}$ \\ ${ }^{1}$ Foundation for Advanced Biomedical Research, Venetian Institute of Molecular Medicine, Padua, Italy \\ ${ }^{2}$ University of Padua, Department of Surgery Oncology and Gastroenterology, Oncology and Immunology Section, Padua, \\ Italy \\ ${ }^{3}$ University of Padua, Department of Physics and Astronomy, Padua, Italy \\ ${ }^{4}$ IRCCS, Istituto Oncologico Veneto, Padua, Italy \\ ${ }^{5}$ Verona University Hospital, Department of Pathology and Diagnostics, Immunology Section, Verona, Italy \\ ${ }^{6}$ Present address: CNR, Institute of Cell Biology and Neurobiology, I-00015 Monterotondo (RM), Italy \\ * These authors contributed equally to this work \\ Correspondence to: Vincenzo Bronte, email: vincenzo.bronte@univr.it
}

Barbara Molon, email: barbara.molon@unipd.it

Fabio Mammano, email: fabio.mammano@unipd.it

Keywords: cancer, photodynamic therapy, nitric oxide, calcium signaling, connexins

Received: January 24, $2015 \quad$ Accepted: February 14, $2015 \quad$ Published: March 12, 2015

This is an open-access article distributed under the terms of the Creative Commons Attribution License, which permits unrestricted use, distribution, and reproduction in any medium, provided the original author and source are credited.

\section{ABSTRACT}

Ionizing and nonionizing radiation affect not only directly targeted cells but also surrounding "bystander" cells. The underlying mechanisms and therapeutic role of bystander responses remain incompletely defined. Here we show that photosentizer activation in a single cell triggers apoptosis in bystander cancer cells, which are electrically coupled by gap junction channels and support the propagation of a $\mathrm{Ca}^{2+}$ wave initiated in the irradiated cell. The latter also acts as source of nitric oxide (NO) that diffuses to bystander cells, in which NO levels are further increased by a mechanism compatible with $\mathrm{Ca}^{2+}$-dependent enzymatic production. We detected similar signals in tumors grown in dorsal skinfold chambers applied to live mice. Pharmacological blockade of connexin channels significantly reduced the extent of apoptosis in bystander cells, consistent with a critical role played by intercellular communication, $\mathrm{Ca}^{2+}$ and $\mathrm{NO}$ in the bystander effects triggered by photodynamic therapy.

\section{INTRODUCTION}

The phrase "bystander effects" was initially adopted in a radiotherapy context to account for responses observed in cellular systems that have not been directly traversed by ionizing radiations but are in close proximity to irradiated cells $[1,2]$. Bystander effects triggered by ionizing radiations in tumor and tumor-infiltrating cells include altered gene expression, DNA damage, mutation, malignant transformation and cell death [3-9]. Bystander responses have been observed also as a consequence of other insults including ultraviolet radiation, heat, chemotherapy agents and photodynamic therapy; however the underlying mechanism and role in clinically relevant scenarios remain incompletely defined [1,2].

Photodynamic therapy is a photochemistry-based approach, adopted primarily in oncology, ophthalmology and dermatology, which uses a light-sensitive chemical, termed photosensitizer, and light of appropriate wavelengths to impart cytotoxicity by generation of 
singlet oxygen [10] and other reactive molecular species [11]. Multiple signaling cascades and sub-cellular organelles are concomitantly affected in cells exposed to photodynamic stress, including adenylate cyclase, receptor tyrosine kinases, MAP kinases, phosphatidylinositol 3-kinase, various protein kinases and phosphatases, transcription factors, ceramide, the plasma membrane, mitochondria and the endoplasmic reticulum (ER) [12-16].

Nitric oxide (NO) has long been implicated in the apoptotic processes triggered by photodynamic therapy [17-19]. Nanomolar concentrations of NO reversibly inhibit cytochrome $\mathrm{c}$ oxidation and mitochondrial respiration; higher concentrations can irreversibly inhibit the respiratory chain [20], leading to the opening of the permeability transition pore and cell death [21, 22]. Its large diffusion coefficient $\left(D_{\mathrm{NO}}=3300 \mu \mathrm{m}^{2} / \mathrm{s}\right)$ [23] makes $\mathrm{NO}$ a prime candidate mediator of bystander responses. In addition, photodynamic stress has been causally associated with disruption of $\mathrm{Ca}^{2+}$ homeostasis and endoplasmic reticulum (ER) depletion [16, 24-26]. NO production by nitric oxide synthases (NOS) is controlled by enzyme binding to calmodulin (CaM)[27]; full activation of target proteins by CaM typically requires occupancy of its four $\mathrm{Ca}^{2+}$-binding sites [28].

Here we used C26GM mouse colon carcinoma cells [29] as a model system to explore bystander effects and the interplay between $\mathrm{NO}$ and $\mathrm{Ca}^{2+}$ signaling in the context of photodynamic therapy.

\section{RESULTS}

We cultured C26GM cells [29] under standard conditions and co-loaded them with the commercially available and well-characterized photosensitizer AlClPc [30-35], the ratiometric fluorescent $\mathrm{Ca}^{2+}$ reporter fura2 [36] and the selective turn-on fluorescent NO reporter $\mathrm{CuFl}[37,38]$. We photo-activated AlClPc for $60 \mathrm{~s}$ within a
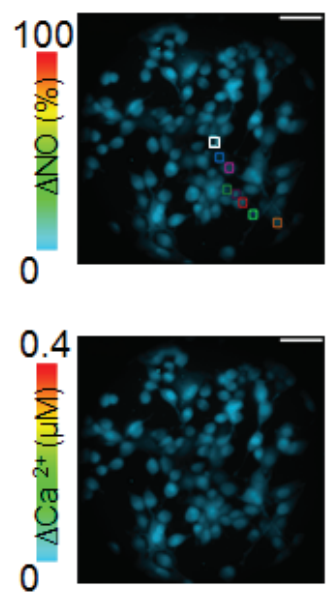

$0 \mathrm{~s}$

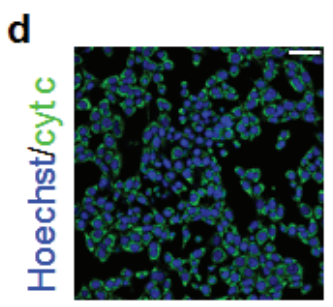

$1 \mathrm{~min}$
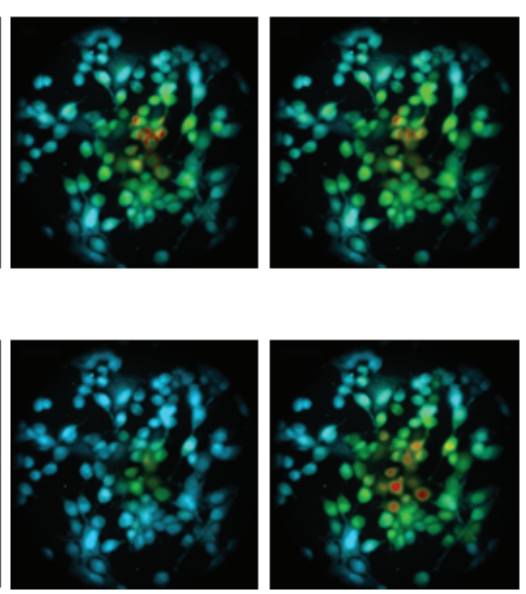

$2 \mathrm{~s}$

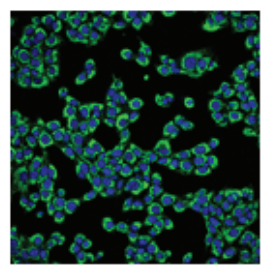

$1 \mathrm{~h}$

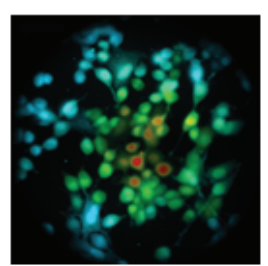

$5 \mathrm{~s}$

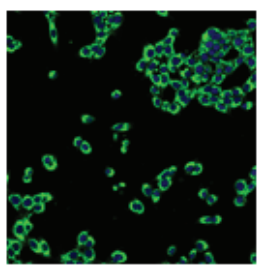

$4 \mathrm{~h}$
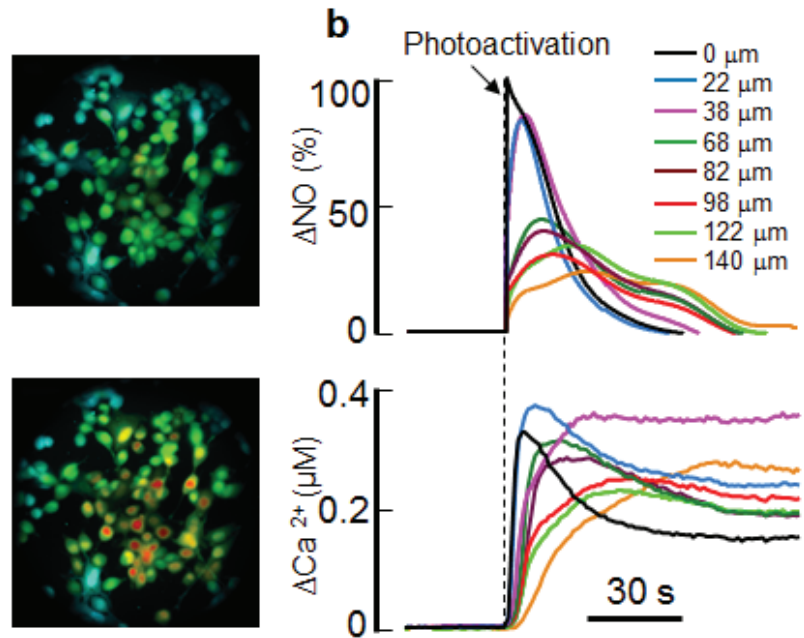

$10 \mathrm{~s}$
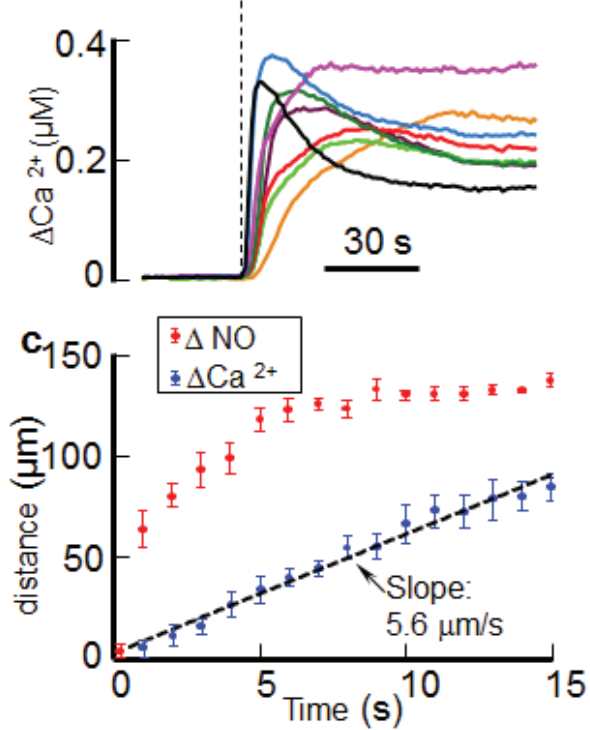

Figure 1: Focal photodynamic injury, i.e. photo-activation of the photosensitizer AlClPc for $60 \mathrm{~s}$ in a single cell of a C26GM mouse colon carcinoma cell culture, triggers $\mathrm{NO}$ and $\mathrm{Ca}^{2+}$ signals that depart from the irradiated cell and rapidly invade bystander cells; these events are followed by cytochrome c release and widespread cell death. (a) Representative false-color images of simultaneously recorded cytosolic $\mathrm{NO}$ (top) and $\mathrm{Ca}^{2+}$ (bottom) concentration changes $(\Delta)$ during focal photodynamic injury; the irradiated cell is encased in a white region of interest (ROI); scale bar, $50 \mu \mathrm{m}$. (b) Single-cell fluorescence traces obtained as pixel averages from the corresponding (colormatched) ROIs in (a); irradiated cell responses are shown as black traces; the vertical dashed line marks the onset of laser irradiation; $\Delta \mathrm{NO}$ data were normalized to the corresponding maximal response in the irradiated cell (see Methods); (c) The distance at which bystander cell signals reach $50 \%$ of their first peak amplitude is shown as a function of time after the onset of focal photodynamic injury. Data are mean \pm s.e.m. from $n=6$ cultures; the dashed line is a least square linear fit with a slope of $5.6 \mu \mathrm{m} / \mathrm{s}$. (d) Cultures were rapidly fixed at shown time points after focal photodynamic injury and immunostained with a cytochrome c antibody and the nuclear counter stain Hoechst; note that images in (d) are from different cultures, whereas those in (a) are all from the same culture; scale bar, $25 \mu \mathrm{m}$. 
a $5 \mu \mathrm{m}$ diameter $(\varnothing)$ area of a single cell in the culture at an irradiance of $60 \mu \mathrm{W} / \mu^{2}$, using a $671 \mathrm{~nm}$ diodepumped solid-state laser connected to a fluorescence microscope. These stimulation conditions, which we refer to as focal photodynamic injury, were maintained for all experiments shown in this article.

By capturing $\mathrm{CuFl}$ and fura-2 fluorescence images in rapid sequence, we determined that AlClPc photoactivation reliably caused elevation $(\Delta)$ of cytosolic NO and $\mathrm{Ca}^{2+}$ levels in the irradiated cell. Within seconds, $\Delta \mathrm{NO}$ and $\Delta \mathrm{Ca}^{2+}$ signals were detected in all (bystander) cells in the $\sim 300 \mu \mathrm{m} \varnothing$ field of view (Figure 1a-c). We obtained similar results in C26GM tumors grown within a dorsal skinfold chamber [39] implanted on BALB/c mice (Supplementary Figure 1), suggesting that the underlying signaling mechanisms are relevant for in vivo photodynamic therapy. We also tested focal photodynamic injury protocol in a different tumor cell line ( fibrosarcoma, MCA-203) in vitro, and we obtained qualitatively similar results both for $\Delta \mathrm{NO}$ and $\Delta \mathrm{Ca}^{2+}$ signals (Supplementary Figure 2). Immunostaining at different time points after focal photodynamic injury revealed cytochrome c release and cell loss progressing radially from the irradiated cell. The process ensued in near-complete depopulation of the field of view within $24 \mathrm{~h}$ following focal photodynamic injury (Figure 1d). $\Delta \mathrm{Ca}^{2+}, \Delta \mathrm{NO}$ and cytochrome $\mathrm{c}$ signals were never detected during or after laser irradiation at 671 $\mathrm{nm}$ if $\mathrm{AlClPc}$ was omitted from the loading solution (3 out of 3 cultures).

Accurate temporal and spatial analysis of $\mathrm{CuFl}$ fluorescence emission (see Methods) highlighted strikingly different kinetics of $\triangle \mathrm{NO}$ and $\mathrm{Ca}^{2+}$ signals. In the irradiated cell, $\Delta \mathrm{NO}$ raised to $90 \%$ of its maximum value, $\Delta \mathrm{NO}_{\max }$, in $<300 \mathrm{~ms}$, whereas the maximum $\Delta \mathrm{Ca}^{2+}$ increment, $\Delta \mathrm{Ca}^{2+}{ }_{\text {max }}$, occurred only $9.8 \pm 1.0 \mathrm{~s}$ after the onset of photostimulation (mean \pm s.e.m., $n=$ 6 cultures). In bystander cells, (i) $\Delta \mathrm{NO}$ peaked once or more depending on the distance from the site of irradiation and returned to baseline within $90 \mathrm{~s}$ in all cells; (ii) $\mathrm{Ca}^{2+}$ signals were progressively delayed at increasing distance from the irradiated cell, corresponding to the cell-tocell propagation of a radial wave proceeding from the irradiated cell and travelling through the bystander cell population with average speed of $5.6 \pm 1.1 \mu \mathrm{m} / \mathrm{s}$ (mean \pm s.e.m., $n=6$ cultures; Figure 1c). As shown in Figure 2, $\Delta \mathrm{NO}_{\text {max }}$ decreased rapidly within $\sim 60 \mu \mathrm{m}$ from the irradiated cell, but less rapidly outside this range. By contrast, $\Delta \mathrm{Ca}^{2+}{ }_{\text {max }}$ showed a clear tendency to increase at increasing distance from the photo-activation site. At the periphery of the field of view, bystander $\Delta \mathrm{Ca}^{2+}{ }_{\text {max }}$ exceed the $\Delta \mathrm{Ca}^{2+}$ of the irradiated cell by $\sim 20 \%$, on average.

To get deeper insight into the intracellular and intercellular dynamics of $\triangle \mathrm{NO}$ signals evoked by focal photodynamic injury, we created a mathematical model

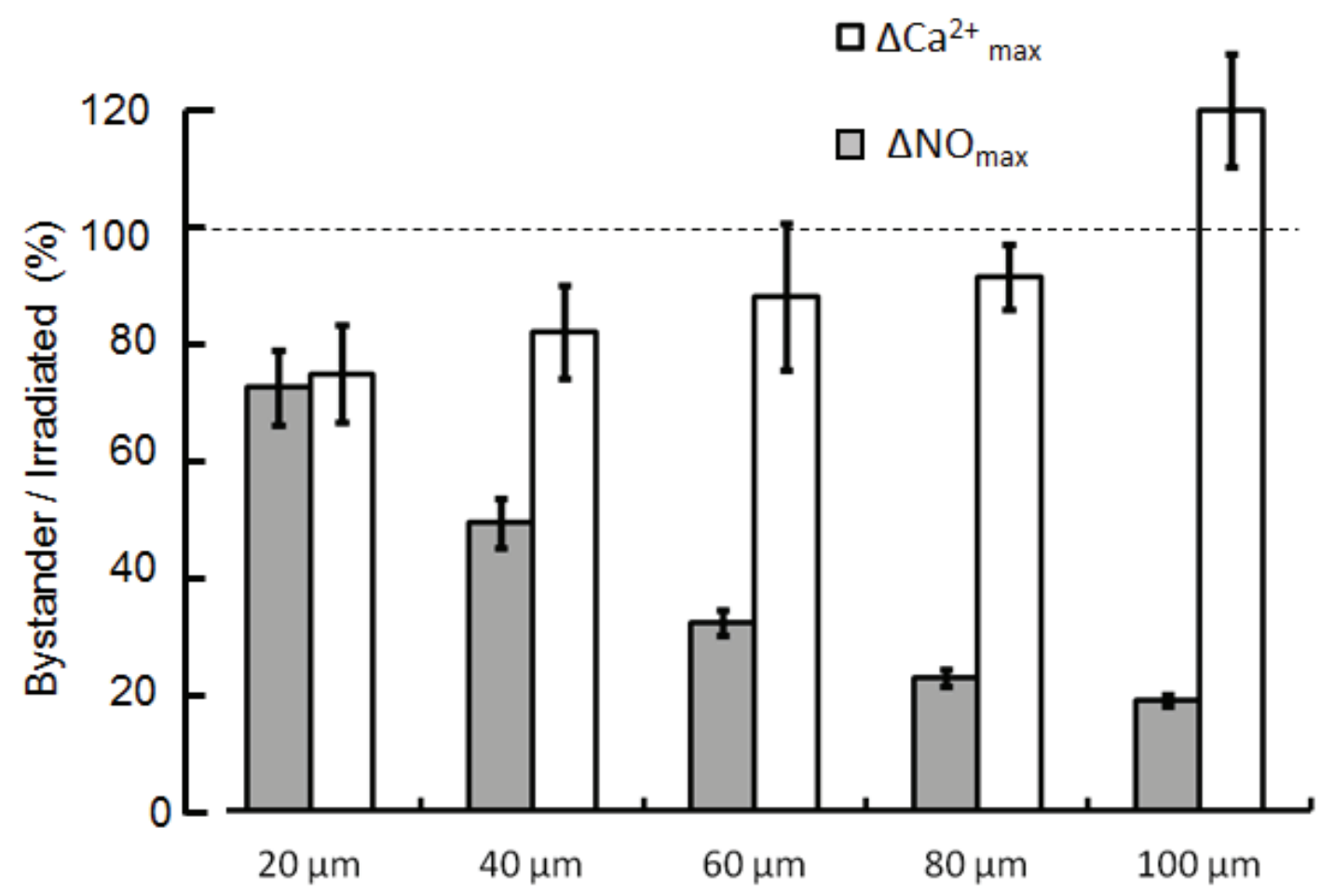

Figure 2: Maximal increments of $\mathrm{NO}\left(\Delta \mathrm{NO}_{\max }\right)$ and $\mathrm{Ca}^{2+}\left(\Delta \mathrm{Ca}^{2+}{ }_{\max }\right)$ levels evoked by focal photodynamic injury in bystander cells as a function of distance from the irradiated cell. Data are mean \pm s.e.m. from $\mathrm{n}=3$ cultures and were normalized to the corresponding maximal response in the irradiated cell. 
(see Methods, Equation 2, Supplementary Methods and Supplementary Figure 3) assuming that NO: (i) is generated within and released from the irradiated cell; (ii) diffuses freely across the extracellular space; (iii) passes freely through cell membranes of bystander cells, in which it is finally detected by pre-loaded CuFl. We used one of the $\triangle \mathrm{NO}$ traces measured in an irradiated cell as input to this model and computed $\Delta \mathrm{NO}$ bystander responses. The results of this analysis (Figure 3 ) show that $\Delta \mathrm{NO}$ responses measured in bystander cells (Figure 3a) largely exceed those predicted based solely on NO diffusion (Figure 3b). The differences between measured and diffusive $\Delta \mathrm{NO}$ signals provide estimates of the alternative generation of NO in bystander cells, likely by its enzymatic production by NOS (Figure 3c). Both the measured NO level increments and the purely diffusive component (estimated by the mathematical model) are monotonically decreasing functions of distance from the irradiated cell (Figure 3d), however the diffusive contribution exhibits a faster spatial rate of decrease. Consequently the ratio of measured minus diffusive (i.e. enzymatic) $\Delta \mathrm{NO}_{\max }$ over diffusive $\Delta \mathrm{NO}_{\max }$ shows a tendency to increase towards the periphery of the

a

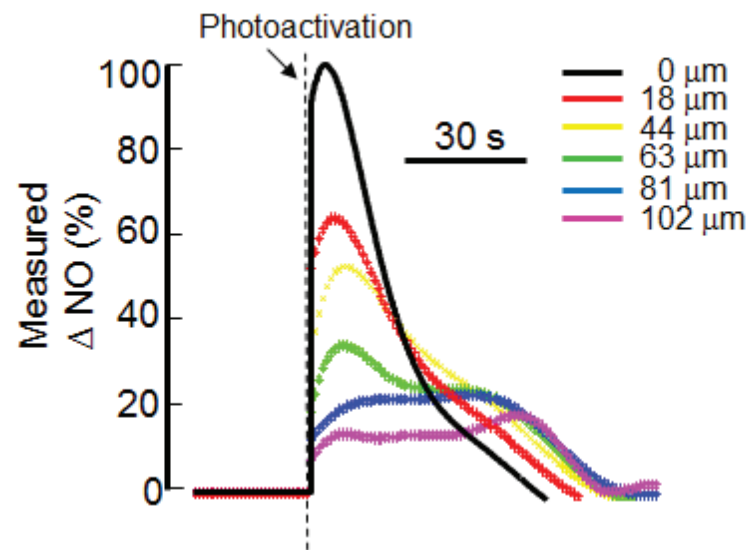

b

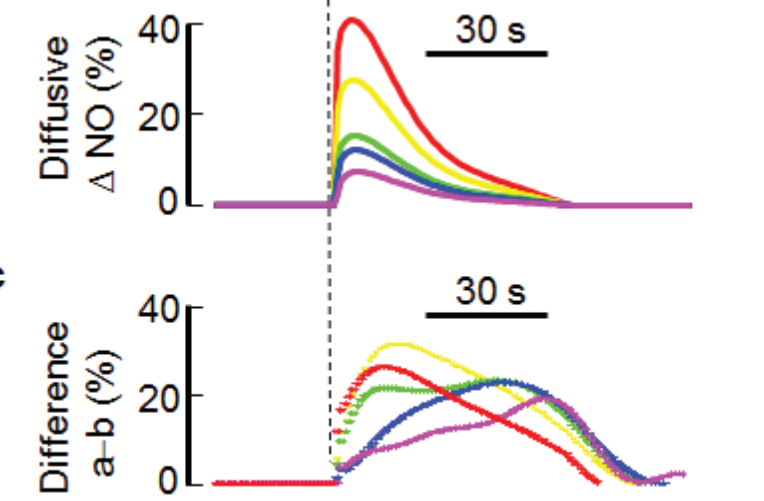

field of view, where it is $>2$ (Figure $3 \mathrm{e}$ ).

Altogether, the results presented in Figures 1-3 suggest that (i) NO is generated almost immediately within the irradiated cell upon AlClPc photo-activation, (ii) diffuses rapidly to bystander cells where (iii) its levels are further increased by a $\mathrm{Ca}^{2+}$-dependent enzymatic production driven by the underlying $\mathrm{Ca}^{2+}$ wave.

To test these hypotheses we performed a series of pharmacological interference experiments. We noted that the relatively low value of the $\mathrm{Ca}^{2+}$ wave speed is compatible with a propagation mechanism whereby diffusion of soluble messengers, such as $\mathrm{IP}_{3}$, through gap junction channels plays a significant role [40]. Gap junction communication has been repeatedly implicated in bystander responses to ionizing radiation [41-46]. Therefore, we assayed C26GM cultures for the presence of functional intercellular channels using a novel, highly sensitive approach [47], based on a combination of patch clamp and voltage imaging with the membrane potential reporter Vf.2.1.Cl [48]. Our results (Figure 4a) indicate that cultured $\mathrm{C} 26 \mathrm{GM}$ cells form functional syncytia since (i) electrical signals delivered to the patch-clamped
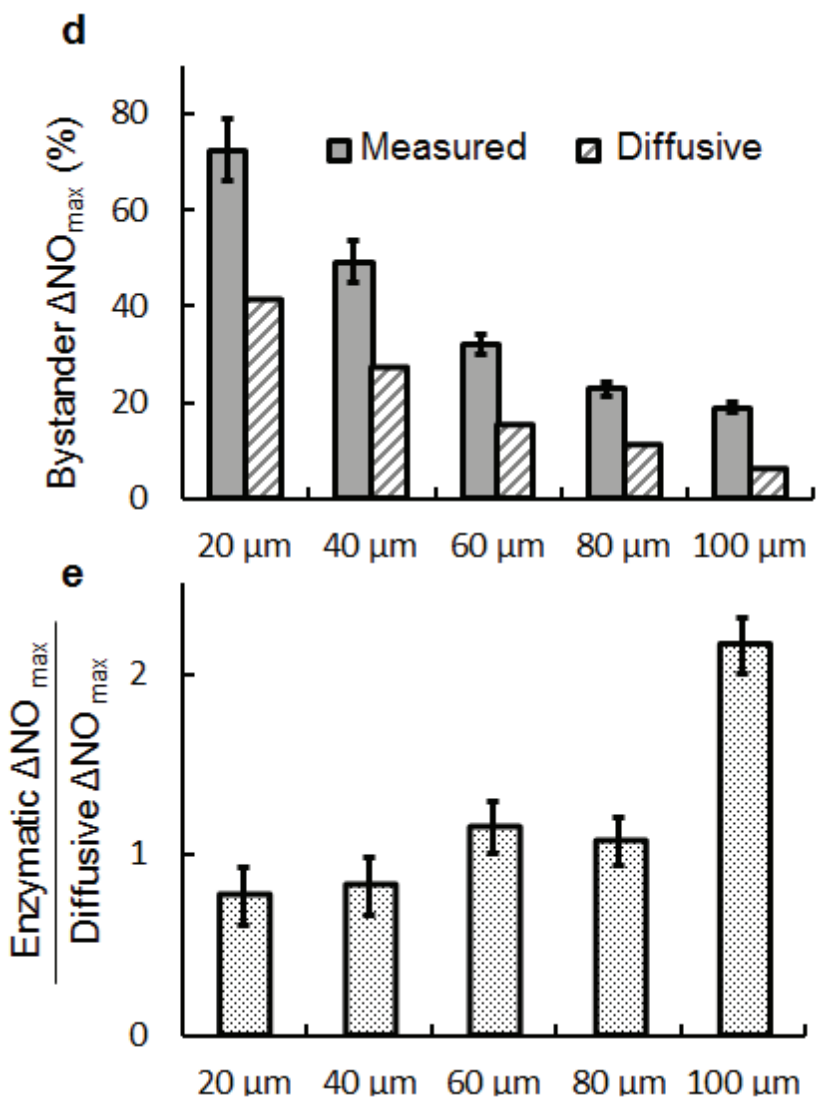

Figure 3: Comparison of experimental and model responses highlights dual contribution to NO signaling in bystander cells. (a) Experimental $\Delta \mathrm{NO}$ traces evoked by focal photodynamic injury at increasing distances from the irradiated cell (black solid line). (b) $\triangle \mathrm{NO}$ signals in bystander cells predicted by a purely diffusive model using the irradiated cell signal in (a) as input and a diffusion coefficient $D_{\mathrm{NO}}=3300 \mu \mathrm{m}^{2} / \mathrm{s}$. (c) Differences between the traces shown in (a) and (b), which we interpret as enzymatic contributions to bystander responses. (d) Maximal measured and diffusive $\mathrm{NO}$ level increments $\left(\Delta \mathrm{NO}_{\text {max }}\right)$ in bystander cells vs. distance from the irradiated cell. (e) Ratio of enzymatic $\Delta \mathrm{NO}_{\max }$ over diffusive $\Delta \mathrm{NO}_{\max }$ vs. distance from the irradiated cell. Measured data in (d) and (e) are mean \pm s.e.m. from $n=3$ cultures; those in (d) were normalized to the corresponding maximal response in the irradiated cell. 
cell invaded a number of other cells in the culture and (ii) electrical coupling was reversibly abrogated by carbenoxolone (CBX), a widely used non-specific inhibitor of connexin-made channels [49]. qPCR analysis for five different connexins expressed in various tumors [50-52] singled out $\mathrm{Cx} 43$ as the predominant isoform expressed by C26GM cells, whereas Cx40 and Cx26 provide minor contributions (Figure 4b).

Figure 5 illustrates the effects of gap junction inhibitors and other drugs on the speed of the intercellular $\mathrm{Ca}^{2+}$ wave, the $\Delta \mathrm{Ca}^{2+}$ and $\Delta \mathrm{NO}$ signals evoked in bystander cells by focal photodynamic injury. Both CBX and flufenamic acid (FFA), another commonly used, non-specific inhibitor of connexin-made channels [49], caused a significant reductions of these three parameters.
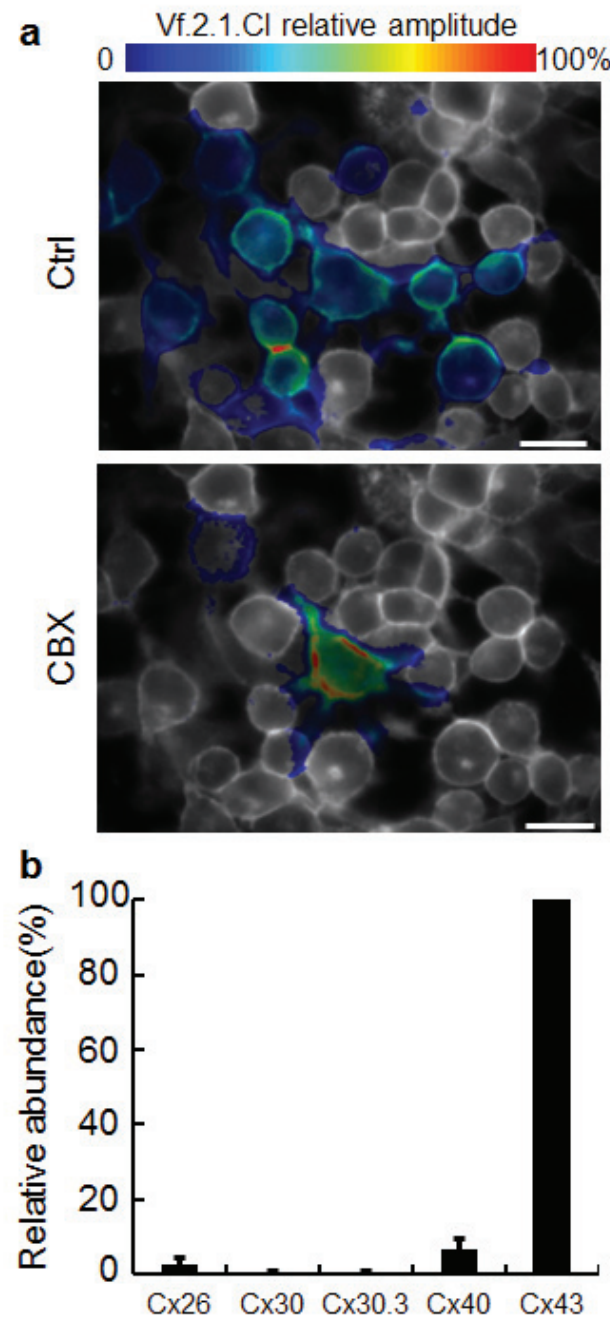

Figure 4: C26GM cells are coupled by gap junction channels. (a) Coupling assay based on voltage imaging with the Vf.2.1.Cl membrane potential sensor shows cells are coupled by gap-junction channels (Ctrl), which can be blocked by carbenoxolone (CBX, $100 \mu \mathrm{M})$; scale bar, $50 \mu \mathrm{m}$. (b) Relative abundance of connexin transcripts in $\mathrm{C} 26 \mathrm{GM}$ cultured cells assayed by qPCR.
We also examined the consequences of perturbing $\mathrm{Ca}^{2+}$ homeostasis prior to focal photodynamic injury. The mild inhibition we observed in $\mathrm{Ca}^{2+}$-free extracellular medium (EGTA) implies negligible contribution of $\mathrm{Ca}^{2+}$ entry to bystander responses. Conversely, all three parameters were significantly reduced if $\mathrm{ER} \mathrm{Ca}^{2+}$ levels were lowered by incubating C26GM cultures with cyclopiazonic acid [53] (CPA), a specific inhibitor of sarco/endoplasmic reticulum $\mathrm{Ca}^{2+}$-ATPase (SERCA pumps), in $\mathrm{Ca}^{2+}$ free medium. The most pronounced reductions of $\triangle \mathrm{NO}$ and $\mathrm{Ca}^{2+}$ bystander signals were obtained with $2 \mathrm{APB}$, a non-specific inhibitor of $\mathrm{IP}_{3}$ receptors $\left(\mathrm{IP}_{3} \mathrm{R}\right)[54] . \Delta \mathrm{NO}$ and $\Delta \mathrm{Ca}^{2+}$ signals and the speed of the intercellular $\mathrm{Ca}^{2+}$ wave were significantly attenuated also by suramin [55], suggesting that paracrine signaling mediated by ATP may play a role. Finally,

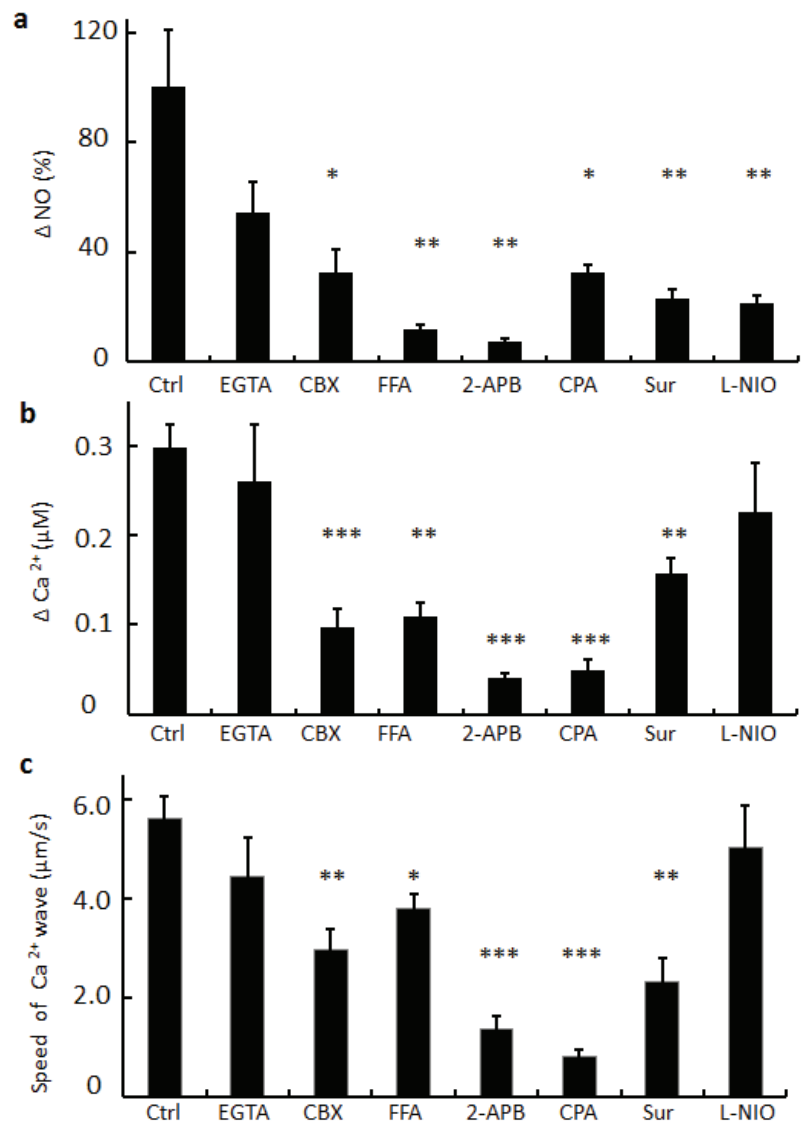

Figure 5: Summary of pharmacological interference experiments. Cells were incubated for 15-20 min with shown drugs prior to focal photodynamic injury; concentrations: EGTA, $100 \mu \mathrm{M}$ (in nominally $\mathrm{Ca}^{2+}$-free medium); CBX, $100 \mu \mathrm{M}$; FFA, $100 \mu \mathrm{M}$; 2-APB, $100 \mu \mathrm{M}$; CPA, $30 \mu \mathrm{M}$; suramin (Sur), 200 $\mu \mathrm{M}$; L-NIO, $10 \mu \mathrm{M}$. Data in $(\mathrm{a}-\mathrm{b})$ are mean \pm s.e.m. of signals measured in 36 randomly selected bystander cells located in an annular region at the periphery of the field of view (between 75 $\mu \mathrm{m}$ and $120 \mu \mathrm{m}$ from the irradiated cell). (a) NO level change $(\triangle \mathrm{NO})$ normalized to the average change measured in control conditions (Ctrl). (b) Cytosolic $\mathrm{Ca}^{2+}$ concentration change $\left(\Delta \mathrm{Ca}^{2+}\right)$. (c) Speed of $\mathrm{Ca}^{2+}$ wave elicited by focal photodynamic injury. 
the potent irreversible NOS inhibitor N-iminoethyl-Lornithine (L-NIO) [56] significantly reduced bystander NO responses (Figure 5a) without affecting bystander $\mathrm{Ca}^{2+}$ signaling (Figure 5b,c).

The results presented so far support the notion that coupling through gap junctions significantly contributes to the $\Delta \mathrm{Ca}^{2+}$ and $\Delta \mathrm{NO}$ signals evoked by focal photodynamic injury, by permitting cell-to-cell propagation of ERand $\mathrm{IP}_{3} \mathrm{R}$-related $\mathrm{Ca}^{2+}$ signals through the network of bystander cells. To evaluate the relevance of gap junction communication also for the apoptotic effects triggered by focal photodynamic injury, we performed additional experiments in C26GM cultures co-loaded with AlClPc and fura-2. At the end of laser irradiation, we switched from $\mathrm{Ca}^{2+}$ imaging to a time-lapse protocol based on staining with propidium iodide and pSIVA-IANBD (Figure 6), an annexin-based polarity sensitive probe for the spatiotemporal or kinetic analysis of apoptosis [57]. Under control conditions, the irradiated cell exhibited detectable pSIVA-IANBD signals as soon as $30 \mathrm{~min}$ after focal photodynamic injury. Both pSIVA-IANBD and propidium iodide signals became detectable in the irradiated cells and the nearest neighbours within $1 \mathrm{~h}$, and reached the limits of the field of view within $3 \mathrm{~h}$ (Figure 6a). These processes were greatly attenuated and slowed down by the gap junction blocker FFA (Figure $6 b)$. No toxicity was observed in C26GM cultures loaded with AlClPc but not exposed to laser irradiation at 671 $\mathrm{nm}$ (Figure 6c). The fraction of C26GM cells exhibiting apoptotic signals as a consequence of focal photodynamic injury increased almost linearly with time, exceeding $15 \%$ of the population within $3 \mathrm{~h}$; this apoptotic rate was significantly reduced, by a factor $>2.5$, in the presence of FFA (Figure 7).

\section{$0 \quad \Delta \mathrm{Ca}^{2+}(\mu \mathrm{M})=0.4$}
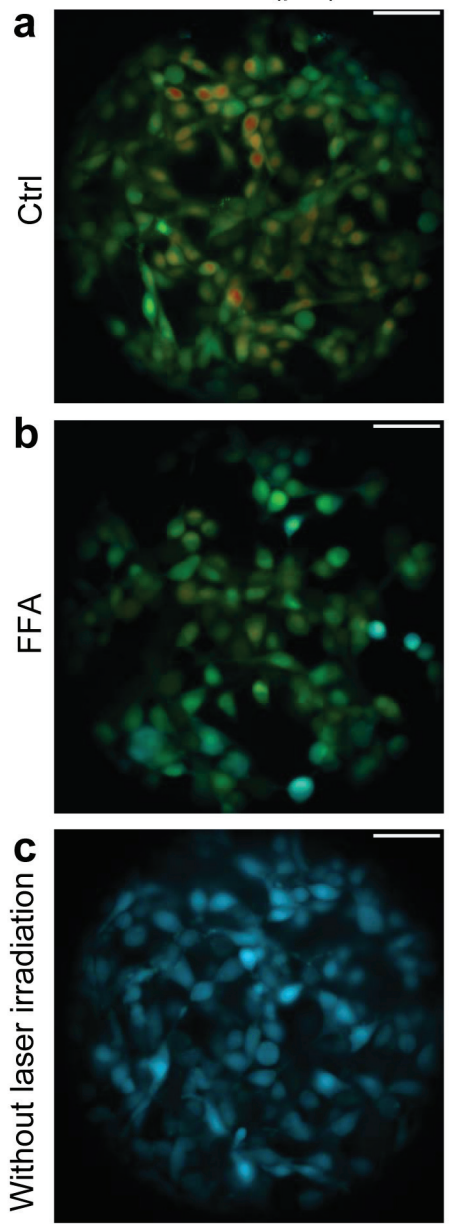

$60 \mathrm{~s}$
pSIVA / PI
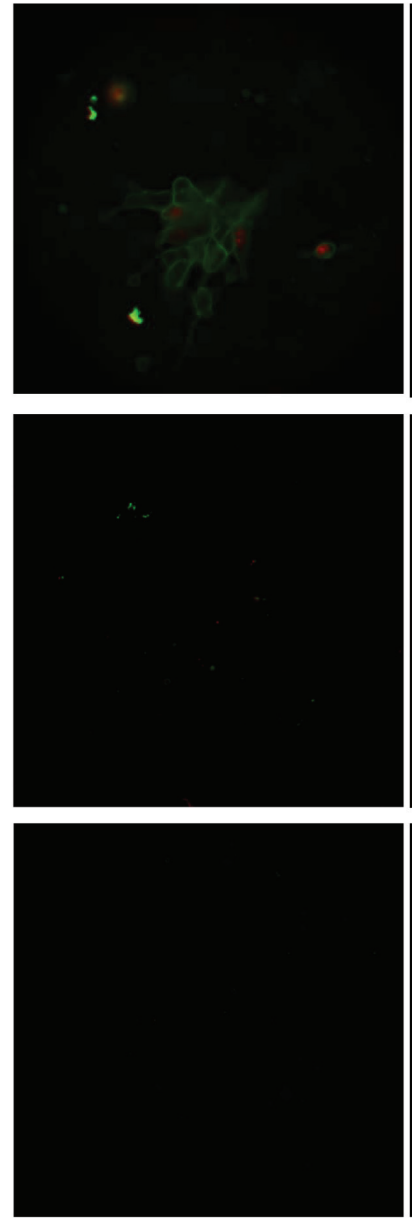

$1 \mathrm{~h}$

$2 \mathrm{~h}$
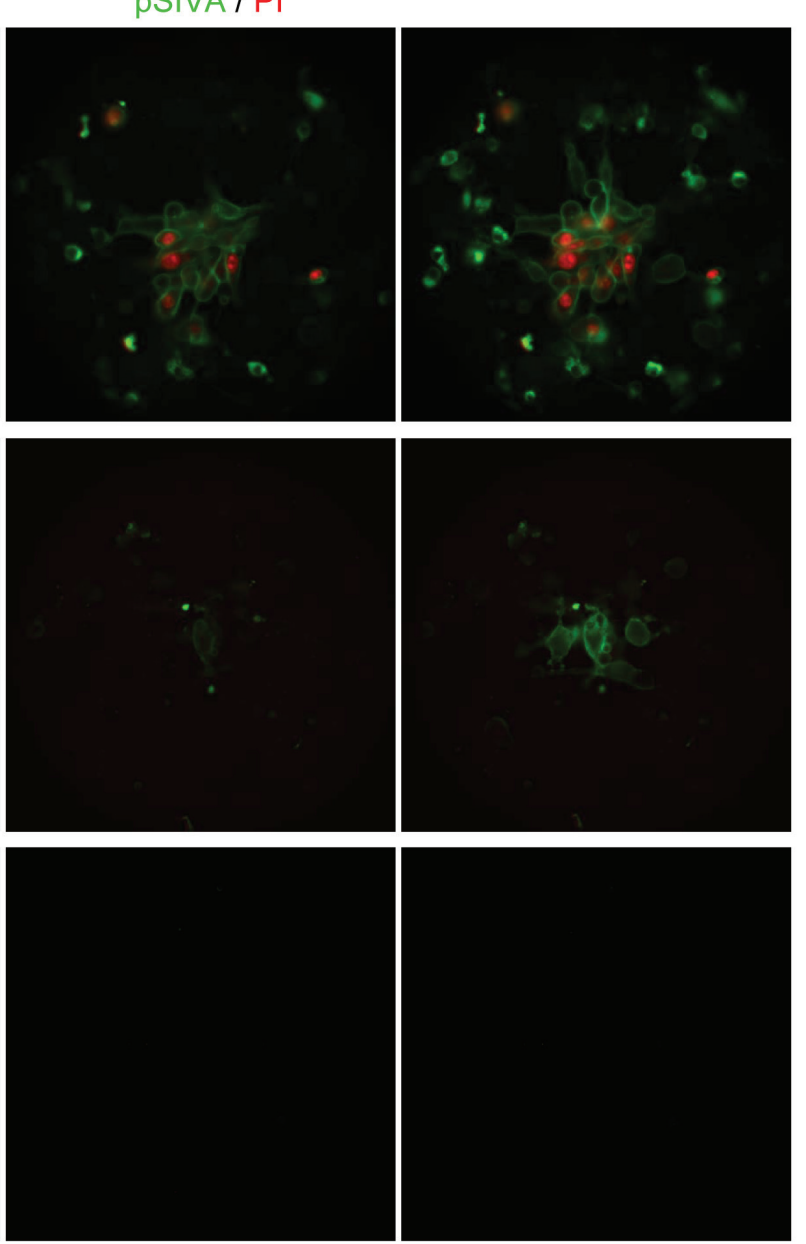

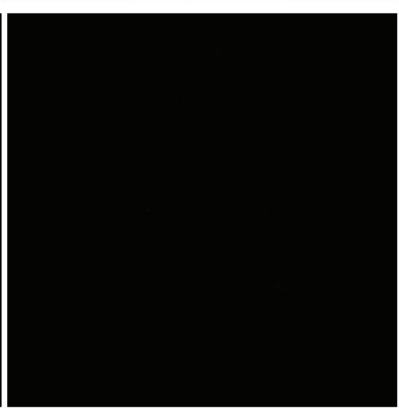

$3 h$

Figure 6: Apoptosis assays. The leftmost panels in $(\mathrm{a}-\mathrm{c})$ are representative false-color images of cytosolic $\mathrm{Ca}^{2+}$ concentration changes $\left(\Delta \mathrm{Ca}^{2+}\right)$ obtained as maximal projection rendering of all frames recorded while imaging C26GM cell cultures for $60 \mathrm{~s}$. The same cultures were then immediately used for time-lapse microscopy, applying the polarity sensitive probe for the spatio-temporal analysis of apoptosis pSIVA-IANBD (pSiva, green) together with propidium iodide (PI, red) as instructed by the manufacturer. In (a) and (b), focal photodynamic injury was performed as usual. In (c), cells were loaded with AlClPc as in (a) and (b), but the laser was not activated. In (b), FFA was maintained throughout the recording. Scale bars, $50 \mu \mathrm{m}$. 


\section{DISCUSSION}

The overall goal of this study was to investigate the interplay between bystander $\mathrm{NO}$ and $\mathrm{Ca}^{2+}$ signaling and the role played by gap junction communication in photodynamic therapy. A striking outcome of our work is that photoactivation in a single cell of a well known photosensitizer, AlClPc [30-35], a condition we refer to as focal photodynamic injury, results in cytochrome-c release and apoptosis, which progress radially from the irradiated cell and cause massive cell demise in the $\sim 300 \mu \mathrm{m} \varnothing$ field of view within $24 \mathrm{~h}$ (Figures 1, 6 and 7). The similarity between the responses evoked by focal photodynamic injury in vitro (Figure 1) and in vivo (Supplementary Figure 1) suggests that these finding may be relevant for photodynamic therapy treatments.

By performing fluorescence imaging with $\mathrm{CuFl}$, a probe that reacts rapidly and specifically with $\mathrm{NO}$ over other potentially interfering reactive molecules [37, 38], we showed here that the irradiated cell acts as a powerful source of NO, which is generated almost immediately upon photo-activation of the photosensitizer and rapidly diffuses to bystander cells. To account for the extremely rapid rise in NO levels during AlClPc photo-activation, we hypothesize that $\mathrm{NO}$ is buffered by this phthalocyanine photosensitizer and released from the cell exposed to laser irradiation. This mechanism is supported by quantum chemistry computations, showing that the metal center of AlClPc binds NO in a redox-dependent manner [58].
Indeed, there is ample evidence that phthalocyanines can be specifically modified to act as highly efficient NO reservoirs and photosensitive $\mathrm{NO}$ donors that also produce singlet oxygen $[59,60]$.

Photoactivation of AlClPc disrupts $\mathrm{Ca}^{2+}$ homeostasis in the irradiated cell and initiates a radial $\mathrm{Ca}^{2+}$ wave. Reactive oxygen and nitrogen species (ROS/ RNS) influence $\mathrm{Ca}^{2+}$ homeostasis via inhibition of PMCA and SERCA pumps and/or by increasing activity of ER release channels (both $\mathrm{IP}_{3}$ Rs and ryanodine receptors) [61, 62]. Current hypotheses propose an alteration of PMCA Tyr589, Met622 and Met831 residues whereas SERCA activity has been shown to be inhibited by ROS/RNS modification of cysteine (and tyrosine) residues [61].

The original analysis method we developed for $\mathrm{CuFl}$ signals (see Methods, Equation 1 and Supplementary Methods) has been instrumental to demonstrate that NO levels increase faster than $\mathrm{Ca}^{2+}$ levels at all locations. Comparison of measured $\triangle \mathrm{NO}$ signals to those predicted by a simple diffusive model indicates that NO diffusion from the irradiated cell accounts only for a fraction of the responses detected by $\mathrm{CuFl}$ in bystander cells (Figure $3)$. We have equated $\left(\mathrm{Ca}^{2+}\right.$ dependent) enzymatic $\mathrm{NO}$ production in bystander cells (Figure 3c) to the difference between measured (Figure $3 \mathrm{a}$ ) and diffusive $\Delta \mathrm{NO}$ signals (Figure $3 b$ ). $\triangle \mathrm{NO}$ responses predicted by the diffusive model were computed assuming that NO influx into bystander cells is not hindered by the plasma membrane. However, the exchange of NO between extracellular

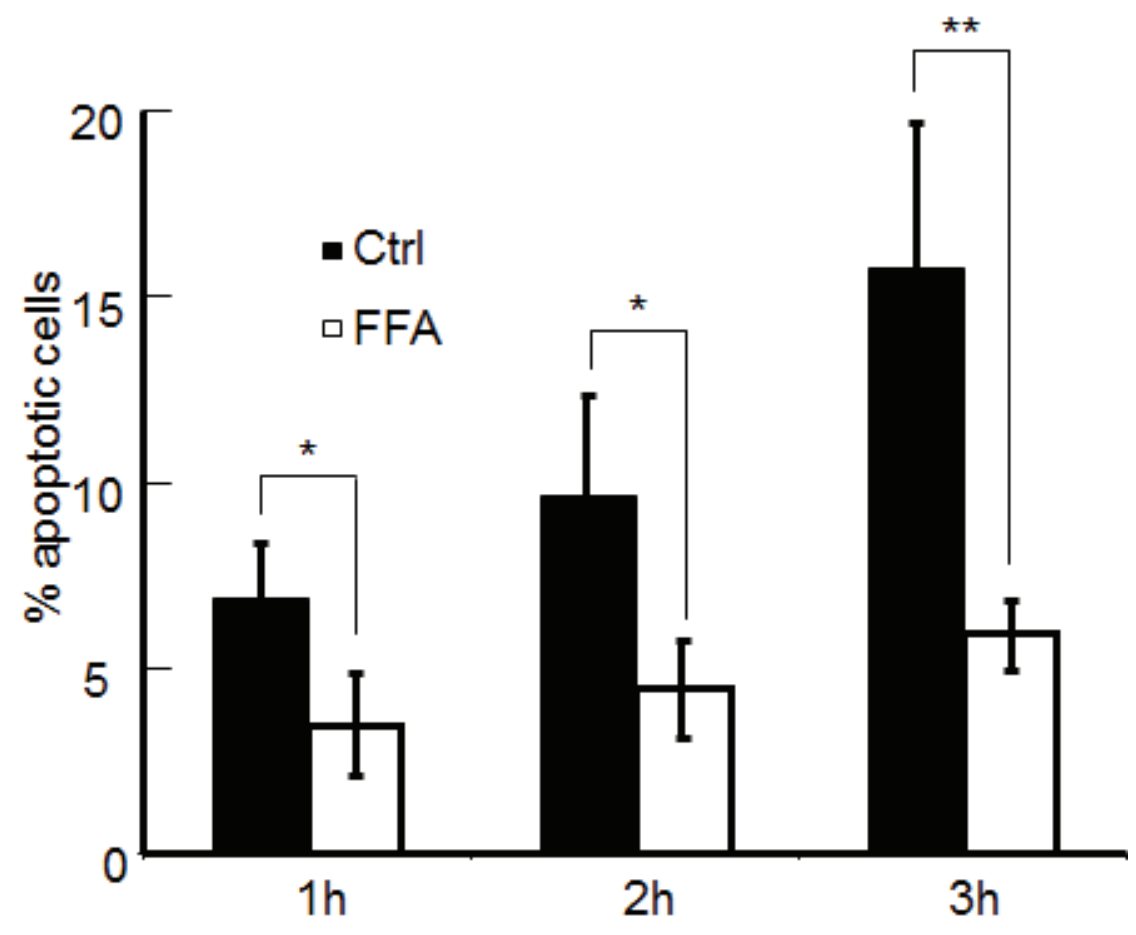

Figure 7: Percentage of apoptotic cells at three time points following focal photodynamic injury in control conditions and in the presence of FFA. Data are mean \pm s.e.m. from $n=3$ cultures in each condition. 
medium and cytoplasm was recently proposed to require connexin hemichannels [63]. If the plasma membrane indeed slows down NO influx, bystander responses in Figure $3 \mathrm{~b}$ are over-estimated and, correspondingly, those in Figure $3 \mathrm{c}$ are under-estimated. Based on our data, the latter accounts for (at least) $\sim 50 \%$ to $\sim 70 \%$ of $\Delta \mathrm{NO}$ signals in bystander cells. Furthermore, the relative importance of enzymatic production versus NO diffusion from the irradiated cell increases with increasing distance from enzymatic NO production (Figure 3d,e). This conclusion is supported by the $>70 \%$ reduction imparted by the NOS inhibitor L-NIO [56] to the $\Delta \mathrm{NO}$ responses of bystander cell at the periphery of the filed of view (Figure 5a).

Altogether, the results of our modeling efforts and pharmacological interference experiments (Figures 3, 5-7 and Supplementary Figure 3) are consistent with a scheme in which NO produced in the irradiated cell diffuses rapidly to bystander cells, where its levels are further increased by a slower mechanism compatible with $\mathrm{Ca}^{2+}$-dependent enzymatic production driven by the underlying $\mathrm{Ca}^{2+}$ wave, which initiates in the irradiated cell and propagates to bystander cells at constant speed (Figure 1c).

In accord with our proposed hypothesis, we have unequivocally showed that C26GM cells are coupled by gap junction channels mainly formed by $\mathrm{Cx} 43$ subunits (Figure 4). Furthermore, pharmacological perturbation of either gap junction communication or intracellular $\mathrm{Ca}^{2+}$ homeostasis reduced significantly the speed of the intercellular $\mathrm{Ca}^{2+}$ wave as well as $\Delta \mathrm{Ca}^{2+}$ and $\Delta \mathrm{NO}$ bystander responses, whereas NOS inhibition by L-NIO [56] significantly reduced $\Delta \mathrm{NO}$ responses without affecting appreciably $\mathrm{Ca}^{2+}$ signaling. Of notice, $\Delta \mathrm{Ca}^{2+}{ }_{\text {max }}$ in bystander cells shows a tendency to increase with distance from the irradiated cell (Figure 2), implying an active, self-regenerative mechanism [40]. In this regard, the sensitivity of $\mathrm{Ca}^{2+}$ wave speed, $\Delta \mathrm{Ca}^{2+}$ and $\Delta \mathrm{NO}$ signals to suramin suggests that a paracrine mechanism involving ATP release may also contribute to $\mathrm{Ca}^{2+}$ wave propagation (as previously reported for bystander radiation damage [45]) and thus also to $\mathrm{Ca}^{2+}$-dependent enzymatic NO production. By contrast, the mild inhibition we observed in $\mathrm{Ca}^{2+}$-free extracellular medium implies negligible contribution of $\mathrm{Ca}^{2+}$ entry to bystander responses [61].

Recent evidence points to a critical involvement of $\mathrm{IP}_{3} \mathrm{R}$-linked $\mathrm{Ca}^{2+}$ signals for the spreading of cytochrome-c induced apoptosis in cellular systems coupled by gap junction channels $[64,65]$. Consistent with this tenet, we found that 2-APB, a well known blocker of $\mathrm{IP}_{3} \mathrm{R}$-dependent calcium release [54] that also inhibits gap junction channels [66], reduced significantly $\mathrm{Ca}^{2+}$ wave speed and caused the most pronounced reduction in both $\Delta \mathrm{Ca}^{2+}$ and $\Delta \mathrm{NO}$ bystander response amplitudes (Figure 5).

The importance of connexins as defense from tumorigenesis and their beneficial role in primary tumors is well supported by several in vitro and in vivo models
$[67,68]$. Our results suggest that potentiating bystander effects upregulating connexins by either targeted drug treatments or viral transduction in primary tumors might enhance the therapeutic potential of photodynamic therapy. They also suggest that temporarily inhibiting gap junction communication might reduce unwanted side effects produced by photodynamic treatment of vascular disorders in the retina[11].

\section{MATERIALS AND METHODS}

\section{Cell culture}

1.5-2.0x $10^{5}$ C26GM mouse colon carcinoma cells [29] were plated on $12 \mathrm{~mm}$ round glass coverslips and cultured at $37^{\circ} \mathrm{C}, 5 \% \mathrm{CO}_{2}$ in Dulbecco's modified Eagle's medium (DMEM, Life technologies), supplemented with $2 \mathrm{mM}$ L-glutamine, $10 \mathrm{mM}$ HEPES, $50 \mu \mathrm{M} 2-$ Mercaptoethanol, $150 \mathrm{U} / \mathrm{mL}$ streptomycin, $200 \mathrm{U} / \mathrm{mL}$ penicillin and 10\% heat-inactivated fetal bovine serum (FBS, Gibco).

\section{Focal photodynamic injury}

AlClPc [30-32] was dissolved in dimethyl sulfoxide at $10 \mathrm{mM}$ concentration and kept in the dark. C26GM cell cultures were incubated with AlClPc $(10 \mu \mathrm{M})$ and co-loaded with fura-2 AM [36] $(15 \mu \mathrm{M})$, for $60 \mathrm{~min}$ at $37^{\circ}$ in DMEM containing pluronic F-127 (0.1\%, w/v), and sulphinpyrazone[69] $(250 \mu \mathrm{M})$. After $60 \mathrm{~min}$ of $\mathrm{AlClPc}$ and fura-2 incubation, cells were additionally loaded at room temperature for 20 min with $\mathrm{CuFl}$ 37,38 at the final concentration of $20 \mu \mathrm{M}$. C26GM cells were then transferred to the stage of an upright fluorescence microscope (Bx51, Olympus) and continually superfused with an extracellular medium containing (in $\mathrm{Mm}$ ): $\mathrm{NaCl}$ $150, \mathrm{KCl} 5, \mathrm{MgCl}_{2} 1$, sodium pyruvate 2 , Hepes-NaOH 10 , D-glucose 5 ( $\mathrm{pH} 7.2,310 \mathrm{mOsm})$. When present, $\mathrm{CaCl}_{2}$ was added at the final concentration of $1 \mathrm{mM}$. For focal photodynamic injury, we photo-activated AlClPc for $60 \mathrm{~s}$ using a CW $671 \mathrm{~nm}$ diode-pumped solid-state laser (Shanghai Dream Lasers) connected to a fluorescence microscope and activated electronically by a transistortransistor-logic (TTL) command under the control of the image acquisition software. To ensure confined photoactivation within a $5 \mu \mathrm{m} \varnothing$ area of a single cell at an irradiance of $60 \mu \mathrm{W} / \mu^{2}$, we launched laser light into a multi-mode step-index fiber optics with $62.5 \mu \mathrm{m}$ core $\varnothing$ and projected a sharp demagnified image of the fiber terminal onto the object plane of the microscope using an achromatic collection lens (Thorlabs) and a $650 \mathrm{~nm}$ short pass dichroic mirror (Edmund Optics) tilted at $45^{\circ}$ and placed right above the objective lens of the microscope. 


\section{$\mathrm{Ca}^{2+}$ and NO imaging}

The ratiometric $\mathrm{Ca}^{2+}$ sensor fura-2 [36] was alternatively excited at $365 \mathrm{~nm}$ and $385 \mathrm{~nm}$ by light from collimated LEDs (Thorlabs) whereas the turnon NO sensor CuFL 37,38 was excited by a $470 \mathrm{~nm}$ LED (Thorlabs). The three LEDs were activated in rapid sequence for $50 \mathrm{~ms}$ each and the activation cycle was repeated once every second. LEDs emissions were filtered through interference band-pass filters centered on the respective peak wavelength, attenuated with a neutral density filter (optical density, 2.12) and conveyed onto the sample by reflection off a DM480HQ dichromatic mirror (Olympus). For both dyes, fluorescence emission was collected through an interference filter (BA495-540HQ, Olympus) using a water immersion objective (40x, N.A. 0.8 , LumPlanFL, Olympus). Images were formed on a sCMOS camera (PCO.Edge, $50 \mathrm{~ms}$ exposure time/frame) controlled by software developed in the laboratory.

Images were analyzed with software developed in the laboratory using the Matlab platform (Release 14, MathWorks, Inc., Natick, MA, USA). Fura-2 and CuFl traces were generated by averaging pixel signals within regions of interest (ROIs) corresponding to individual cells located at different distance from the irradiated cell. Pseudocolor images were generated using the huesaturation-value (HSV) visualization algorithm [70]. Hue was used to represent fluorescence changes; value (brightness) carried pixel intensity from a reference image that was either updated on a frame-by-frame basis or obtained as an average over a specified number of frames; saturation was set to 1.0. Frames so constructed were converted to ordinary RGB images by a single call to the Matlab library function hsv2rgb, and displayed.

\section{Analysis of NO signals}

We converted $\mathrm{CuFl}$ fluorescence emission $F$ at time $t$ into NO concentration using the formula

$$
[\mathrm{NO}](t)=\frac{1}{k_{\mathrm{oN}}} \cdot \frac{d}{d t}\left(\frac{F(t)}{F_{0}}\right) \cdot\left(13.14-\frac{F(t)}{F_{0}}\right)^{-1}
$$

Equation 1

where $\mathrm{k}_{\mathrm{ON}}$ is the reaction rate of the CuFlNO complexation reaction, $F_{0}$ is the (constant) prestimulus fluorescence and square brackets denote molar concentration. Equation 1 is derived in the Supplementary Methods. To estimate numerically the temporal derivative of the recorded signals, $F(\mathrm{t}) / F_{0}$ data collected after the onset of AlClPc photo-activation were interpolated with a polynomial of order $N$ comprised between 8 and 15 using the least square algorithm; the resulting polynomial was then differentiated analytically. Since $\mathrm{k}_{\mathrm{ON}}$ is unknown[37,
38], all data are presented as percent of the maximal signal computed in the irradiated cell using Equation 1.

\section{Mathematical model of NO diffusion}

The maximal diffusive contribution to NO bystander signals was estimated assuming that NO diffuses freely in the extracellular space as well as across cell membranes. Under these conditions NO concentration is determined by the diffusion equation [71]:

$$
\frac{\partial[\mathrm{NO}](t)}{\partial t}=D_{\mathrm{NO}} \nabla^{2}[\mathrm{NO}](t)
$$

$[\mathrm{NO}](t)$ measured in the irradiated cell using Equation 1 was used as input to the model and Equation 2 was solved numerically in three dimensions using a finite difference approach with a time step $\Delta t=50 \mu \mathrm{s}$ and $\mathrm{D}_{\mathrm{NO}}=3300 \mu \mathrm{m}^{2} / \mathrm{s}$. The domain of Equation 2 and the corresponding boundary conditions are illustrated in Supplementary Figure 3. The domain volume was subdivided in voxels with $10 \mu \mathrm{m}$ size in the $z$ direction and $2 \mu \mathrm{m}$ size in the $x$ and $y$ directions. Cells were modelled as having a polygonal base in the $x-y$ plane $(z$ $=0$ ), reproducing their experimental distribution, and a height $z=10 \mu \mathrm{m}$. A reflecting boundary at $z=0 \mu \mathrm{M}$ was introduced to describe the effect of the underlying glass, whereas absorbing boundaries were imposed at the horizontal plane $z=150 \mu \mathrm{m}$ and on the vertical planes located at $x \pm 300 \mu \mathrm{m}$ and $y \pm 300 \mu \mathrm{m}$.

\section{Analysis of $\mathrm{Ca}^{2+}$ signals}

$\mathrm{Ca}^{2+}$ signals were measured as fura- 2 emission ratio changes, $\Delta R=R(\mathrm{t})-R(0)$, where $\mathrm{t}$ is time, $R(t)$ is fura-2 emission intensity excited at $365 \mathrm{~nm}$ divided by the intensity excited at $385 \mathrm{~nm}$, and $R(0)$ indicates prestimulus ratio. Estimates of the cytosolic free calcium concentration $\left(\left[\mathrm{Ca}^{2+}\right]_{\mathrm{c}}\right)$ were obtained from ratio values using the Grynkiewicz formula [36]:

$$
\left[\mathrm{Ca}^{2+}\right]_{\mathrm{c}}(t)=K_{d} \cdot\left(\frac{R(t)-R_{\text {min }}}{R_{\text {max }}-R(t)}\right) \cdot\left(\frac{F_{f}}{F_{b}}\right)
$$

Equation 3

$$
\mathrm{R}_{\text {min }}=0.42 \text { and } \mathrm{R}_{\max }=13.04 \text { refer to minimum }
$$
and maximum ratio values recorded in situ with $10 \mu \mathrm{M}$ ionomycin in the presence of $2 \mathrm{mM}$ EGTA solution and $20 \mathrm{mM} \mathrm{Ca}^{2+}$ solution, respectively, $\mathrm{F}_{\mathrm{f}} / \mathrm{F}_{\mathrm{b}}=11.06$ is the ratio of the fluorescence values of the $\mathrm{Ca}^{2+}-$ free and $\mathrm{Ca}^{2+}$ bound forms at $385 \mathrm{~nm}$ and $\mathrm{K}_{\mathrm{d}}$, the dissociation constant of fura2 at $22^{\circ} \mathrm{C}$, was assumed to be $280 \mathrm{nM}$. 


\section{Gap junction coupling assay}

To visualize gap junction coupling in C26GM cells, we used a novel method based on a combination of patch-clamp and imaging of transmembrane potential [47]. Briefly, glass capillaries for patch clamp recordings were formed on a vertical puller (PP-83, Narishige, Japan) from 1.5-mm outer $\varnothing$ borosilicate glass (G85150T-4, Warner Instruments) and filled with an intracellular solution containing (in $\mathrm{mM}$ ): $\mathrm{KCl} 134, \mathrm{NaCl} 4, \mathrm{MgCl}_{2}$ 1, HEPES 20, EGTA 10 (adjusted to $\mathrm{pH} 7.3$ with $\mathrm{KOH}$ ) and filtered through $0.22-\mu \mathrm{m}$ pores (Millipore). Pipette resistances were 3-4 MOhm when immersed in the bath. $\mathrm{C} 26 \mathrm{GM}$ cells were incubated for $15 \mathrm{~min}$ at $37^{\circ} \mathrm{C}$ in extracellular medium (see above) supplemented with $200 \mathrm{nM}$ of Vf2.1.Cl, a highly sensitive fluorescent sensors of plasma membrane potential [48] kindly provided by Roger Y. Tsien (University of California, San Diego) and pluronic $\mathrm{F}-127(0.1 \% \mathrm{w} / \mathrm{v})$. A cell located near the centre of the field of view was maintained under whole cell voltage clamp conditions using a patch clamp amplifier (EPC-7, HeKa). The patched cell was stimulated by a sinusoidal voltage command (also named carrier wave) delivered to the patch clamp amplifier (frequency $0.5 \mathrm{~Hz}$, amplitude $35 \mathrm{mV}$ ). Current and voltage were filtered at $3 \mathrm{kHz}$ by an 8 pole Bessel filter and sampled at $20 \mathrm{kHz}$ using a standard laboratory interface (Digidata 1440A, Molecular Devices) controlled by the PClamp 10 software (Molecular Devices). During electrical stimulation, $\mathrm{Vf2}$.1.Cl fluorescence images were formed using a water immersion objective (60x, 1.0 NA, Fluor, Nikon) and projected on the sCMOS camera. Vf.2.1.Cl fluorescence was excited by light from the $470 \mathrm{~nm}$ LED, filtered through a BP460-480 filter (Olympus), attenuated with a neutral density filter (optical density, 2.12) and conveyed onto the sample by reflection off a 515 dcxr dichromatic mirror (Chroma). Fluorescence emission was collected through an ET535/30M filter (Chroma). Vf.2.1.Cl signals elicited by the carrier wave and propagated through the gap junction network were measured as relative changes of fluorescence emission intensity $\left(\Delta \mathrm{F} / \mathrm{F}_{0}\right)$. At each location, the amplitude of the $\Delta \mathrm{F} / \mathrm{F}_{0}$ signal at the frequency of the carrier wave was extracted using a phase-sensitive detection algorithm (for details, see [47]) and used to quantify the spatial extent of the gap junction network. For these recordings, images were acquired continuously at 10 frames per second with $100 \mathrm{~ms}$ exposure time. To synchronize image acquisition and patch clamp recordings, we sampled the $5 \mathrm{~V}$ pulse (FVAL) that signals active exposure of the sCMOS camera.

\section{Apoptosis assay}

C26GM cell were co-loaded with AlCIPc and fura2 as described above. After focal photodynamic injury,
pSIVA-IANBD and Propidium Iodide (Imgenex) were added directly to the extracellular medium, enriched with $\mathrm{CaCl}_{2}$ to a final concentration of $2.5 \mathrm{mM}$, and cells were imaged by time-lapse microscopy for up to 3 hours. pSIVA-IANBD fluorescence emission was imaged with the same settings used for Vf.2.1.Cl. Propidium Iodide was excited by light from a $535 \mathrm{~nm}$ LED attenuated with a neutral density filter (optical density, 2.12) and reflected off a DM560 dichromatic mirror (Olympus), and its fluorescence emission was collected through a long-pass emission filter (590LPV2, Chroma).

\section{Immunofluorescence and confocal microscopy}

C26GM cells, treated or not with AlClPc, were fixed in $4 \%$ paraformaldehyde for $20 \mathrm{~min}$ at room temperature, rinsed in phosphate buffered saline (PBS), and permeabilized with $0.1 \%$ Triton $\mathrm{X}-100$, dissolved in bovine serum albumin (BSA) 1\% solution and incubated with anti-cytochrome $\mathrm{c}$ antibody( BD Pharmingen). The Alexa Fluor 488- conjugated goat Anti-Mouse IgG (4 $\mu \mathrm{g} /$ $\mathrm{ml}$ ) was purchased from Life Technologies. Nuclei were counterstained with $1 \mu \mathrm{g} / \mathrm{ml}$ Hoechst 33258 and mounted with ProLong (Life technologies). Images were acquired using a confocal microscope (TCS SP5, Leica) equipped with an oil-immersion objective $(63 \times, 1.25$ NA, HCX PL APO, Leica). Laser line intensities and detector gains were carefully adjusted to minimize signal bleed through outside the designated spectral windows.

\section{qPCR}

mRNA was extracted from C26GM cultured cells using RNAeasy kit (Qiagen). cDNA was obtained by reverse transcription of mRNA with random hexamers and ThermoScript RT-PCR system (Life technologies) according to the manufacturer instructions. qPCR was performed on cDNA to amplify Cx26, Cx30, Cx30.3, $\mathrm{Cx} 40, \mathrm{Cx} 43$ and was normalized to GAPDH expression. Amplification was carried out using SYBR Green (Applied Biosystems) on the ABI 7700 sequence detection system equipped with ABI Prism 7700 SDS software (Applied Biosystems) through the following amplification cycles: $50^{\circ} \mathrm{C}: 2 \mathrm{~min}, 95^{\circ} \mathrm{C}: 10 \mathrm{~min}, 95^{\circ} \mathrm{C}: 15 \mathrm{sec}, 60^{\circ} \mathrm{C}: 1 \mathrm{~min}$ (40 cycles). For real-time PCR the following primers were used: Cx26f: 5'-CGG AAG TTC ATG AAG GGA GAG AT -3'; Cx26r: 5'-GGT CTT TTG GAC TTT CCT GAG CA -3'; Cx30f: 5'- GTC ATC GGT GGC GTG AAC AAG CAC -3'; Cx30r: 5'- GAG CAG CAT GCA AAT CAC GGA TGC -3'; Cx30.3f: 5'- TCA AAC ATG GGC CCA ATG -3'; Cx30.3r: 5'- GGG AGT CAC AGA GCA AGC -3'; Cx40f: 5'- CTG TCC CCA CCC AGT CAA CT -3'; Cx40r: 5'- CCG TTT GTC ACT ATG GTA GC -3'; Cx43f: 5'- TAC CAC GCC ACC ACC GGC CCA -3'; Cx43r: 5'- GGC ATTTTGGCTGTCGTCAGGGAA 
-3'; GAPDHf: 5'-ATG TGT CCG TCG TGG ATC TGA C-3'; GAPDHr: 5'-AGA CAA CCT GGT CCT CAG TGT AG-3'.

Quantification of connexin mRNA expression relative to GAPDH was performed using the $\Delta \Delta \mathrm{CT}$ method.

\section{Data analysis and statistics}

Unless otherwise stated, statistical comparisons of means for paired samples were made by one-way heteroscedastic Student t-test. p-values are indicated by letter $p$ and $p<0.05$ was selected as the criterion for statistical significance. In figures, asterisks were used as follows: $* x \leq 0.05 ; * * p \leq 0.01 ; * * * p \leq 0.001$.

\section{ACKNOWLEDGMENTS}

Partially supported by a University of Padua grant (prot. CPDA094904), by grants from the Italian Ministry of Health, Italian Ministry of Education (FIRB cup: B31J11000420001), Universities, and Research, Italian Association for Cancer Research (AIRC, grants 6599, 12182 and 14103) and by a grant from the Italian Ministry of Health (BANDO GIOVANI RICERCATORI 2009 GR-2009-1558698). A.H.R.A. was supported by Cariparo Fundation Fellowship.

\section{CONFLICT OF INTEREST}

The authors declare no conflict of interest.

\section{Author contributions}

B.C., V.B., B.M., F.M.,: conception and design, provision of study material, collection and/or assembly of data, data analysis and interpretation, manuscript writing;

B.C., F.C, M.B.,A.H.R.A. A.P, V.Z. : experiment performing; collection and/or assembly of data.

$\mathrm{SC}$ : development of CuFL analysis method, modeling NO diffusion, data analysis.

\section{Abbreviations}

2-APB: 2 Aminoethoxydiphenyl borate

AlPCc: Aluminum Phthalocyanine Chloride

$\mathrm{Ca} 2+$ : Calcium ion

CaM: Calmodulin

CBX: Carbenoxolone

CuFL: $\{4,5-B i s[(6-(2-e t h o x y-2-o x o e t h o x y)-2-$

methylquinolin-8 ylamino) methyl] 6-hydoxy-3-

oxo-3H-xanthen-9-yl\} benzoic acid FL

CPA: Cyclopiazonic Acid

Cx: Connexin
Cyt C: Cytochrome c

EGTA: Ethylene Glycol-bis(beta-aminoethyl ether)-

N,N,N',N'-Tetraacetic Acid

ER: Endoplasmatic Reticulum

FFA: Flufenamic Acid

GM-CSF: Granulocyte Macrophage - Colony

Stimulating Factor

IP3: Inositol 1,4,5-trisphosphate

IP3R: IP3 receptors

L-NAME: L-N $\omega$-nitroL-Arginine Methyl Ester

L-NIO: N-iminoethyl-L-ornithine

NO: Nitric Oxide

NOS: Nitric Oxide Synthase

PI:Propidium Iodide

PMCA: Plasma membrane Ca2+ATPase

PSIVA: Polarity Sensitive Indicator of Viability and Apoptosis

RNS: Reactive Nitrogen Species

ROS: Reactive Oxygen Species

ROI: Region Of Interest

SERCA: Sarco/Endoplasmatic reticulum

$\mathrm{Ca}^{2+}$ ATPase

\section{REFERENCES}

1. Prise KM and O'Sullivan JM. Radiation-induced bystander signalling in cancer therapy. Nat Rev Cancer. 2009; 9(5):351-360.

2. Butterworth KT, McMahon SJ, Hounsell AR, O'Sullivan JM and Prise KM. Bystander signalling: exploring clinical relevance through new approaches and new models. Clin Oncol (R Coll Radiol). 2013; 25(10):586-592.

3. Iyer R, Lehnert BE and Svensson R. Factors underlying the cell growth-related bystander responses to alpha particles. Cancer research. 2000; 60(5):1290-1298.

4. Little JB. Lauriston S. Taylor lecture: nontargeted effects of radiation: implications for low-dose exposures. Health physics. 2006; 91(5):416-426.

5. Koturbash I, Rugo RE, Hendricks CA, Loree J, Thibault B, Kutanzi K, Pogribny I, Yanch JC, Engelward BP and Kovalchuk O. Irradiation induces DNA damage and modulates epigenetic effectors in distant bystander tissue in vivo. Oncogene. 2006; 25(31):4267-4275.

6. Nagasawa H, Peng Y, Wilson PF, Lio YC, Chen DJ, Bedford JS and Little JB. Role of homologous recombination in the alpha-particle-induced bystander effect for sister chromatid exchanges and chromosomal aberrations. Radiation research. 2005; 164(2):141-147.

7. Nagasawa H, Huo L and Little JB. Increased bystander mutagenic effect in DNA double-strand break repairdeficient mammalian cells. International journal of radiation biology. 2003; 79(1):35-41.

8. Lyng FM, Seymour CB and Mothersill C. Early events in the apoptotic cascade initiated in cells treated with medium from the progeny of irradiated cells. Radiation protection 
dosimetry. 2002; 99(1-4):169-172.

9. Mothersill C and Seymour C. Radiation-induced bystander effects, carcinogenesis and models. Oncogene. 2003; 22(45):7028-7033.

10. Weishaupt KR, Gomer CJ and Dougherty TJ. Identification of singlet oxygen as the cytotoxic agent in photoinactivation of a murine tumor. Cancer research. 1976; 36(7 PT 1):23262329.

11. Celli JP, Spring BQ, Rizvi I, Evans CL, Samkoe KS, Verma $\mathrm{S}$, Pogue BW and Hasan T. Imaging and Photodynamic Therapy: Mechanisms, Monitoring, and Optimization. Chemical Reviews. 2010; 110(5):2795-2838.

12. Castano AP, Demidova TN and Hamblin MR. Mechanisms in photodynamic therapy: part one-photosensitizers, photochemistry and cellular localization. Photodiagn Photodyn. 2004; 1(4):279-293.

13. Castano AP, Demidova TN and Hamblin MR. Mechanisms in photodynamic therapy: Part three- Photosensitizer pharmacokinetics, biodistribution, tumor localization and modes of tumor destruction. Photodiagn Photodyn. 2005; 2(2):91-106.

14. Castano AP, Demidova TN and Hamblin MR. Mechanisms in photodynamic therapy: part two-cellular signaling, cell metabolism and modes of cell death. Photodiagnosis Photodyn Ther. 2005; 2(1):1-23.

15. Uzdensky AB. Signal transduction and photodynamic therapy. Curr Signal Transd T. 2008; 3(1):55-74.

16. Buytaert E, Dewaele $M$ and Agostinis P. Molecular effectors of multiple cell death pathways initiated by photodynamic therapy. Biochimica et biophysica acta. 2007; 1776(1):86-107.

17. Gupta $\mathrm{S}, \mathrm{Ahmad} \mathrm{N}$ and Mukhtar H. Involvement of nitric oxide during phthalocyanine (Pc4) photodynamic therapymediated apoptosis. Cancer research. 1998; 58(9):17851788.

18. Dalbasti T, Cagli S, Kilinc E, Oktar N and Ozsoz M. Online electrochemical monitoring of nitric oxide during photodynamic therapy. Nitric Oxide-Biol Ch. 2002; 7(4):301-305.

19. Reeves KJ, Reed MWR and Brown NJ. Is nitric oxide important in photodynamic therapy? J Photoch Photobio B. 2009; 95(3):141-147.

20. Brown GC. Regulation of mitochondrial respiration by nitric oxide inhibition of cytochrome c oxidase. BbaBioenergetics. 2001; 1504(1):46-57.

21. Rasola A and Bernardi P. Mitochondrial permeability transition in $\mathrm{Ca} 2+$-dependent apoptosis and necrosis. Cell calcium. 2011; 50(3):222-233.

22. Giorgio V, von Stockum S, Antoniel M, Fabbro A, Fogolari F, Forte M, Glick GD, Petronilli V, Zoratti M, Szabo I, Lippe $G$ and Bernardi P. Dimers of mitochondrial ATP synthase form the permeability transition pore. Proceedings of the National Academy of Sciences of the United States of America. 2013; 110(15):5887-5892.
23. Malinski T, Taha Z, Grunfeld S, Patton S, Kapturczak M and Tomboulian P. Diffusion of Nitric-Oxide in the Aorta Wall Monitored in-Situ by Porphyrinic Microsensors. Biochemical and biophysical research communications. 1993; 193(3):1076-1082.

24. Buytaert E, Callewaert G, Hendrickx N, Scorrano L, Hartmann D, Missiaen L, Vandenheede JR, Heirman I, Grooten J and Agostinis P. Role of endoplasmic reticulum depletion and multidomain proapoptotic BAX and BAK proteins in shaping cell death after hypericin-mediated photodynamic therapy. FASEB journal : official publication of the Federation of American Societies for Experimental Biology. 2006; 20(6):756-758.

25. Granville DJ, Ruehlmann DO, Choy JC, Cassidy BA, Hunt DWC, van Breemen C and McManus BM. Bcl-2 increases emptying of endoplasmic reticulum $\mathrm{Ca} 2+$ stores during photodynamic therapy-induced apoptosis. Cell calcium. 2001; 30(5):343-350.

26. Shahzidi S, Cunderlikova B, Wiedlocha A, Zhen Y, Vasovic V, Nesland JM and Peng Q. Simultaneously targeting mitochondria and endoplasmic reticulum by photodynamic therapy induces apoptosis in human lymphoma cells. Photoch Photobio Sci. 2011; 10(11):1773-1782.

27. Groves JT and Wang CCY. Nitric oxide synthase: models and mechanisms. Curr Opin Chem Biol. 2000; 4(6):687695.

28. Faas GC, Raghavachari S, Lisman JE and Mody I. Calmodulin as a direct detector of $\mathrm{Ca} 2+$ signals. Nature neuroscience. 2011; 14(3):301-304.

29. Bronte V, Serafini P, De Santo C, Marigo I, Tosello V, Mazzoni A, Segal DM, Staib C, Lowel M, Sutter G, Colombo MP and Zanovello P. IL-4-induced arginase 1 suppresses alloreactive $\mathrm{T}$ cells in tumor-bearing mice. $\mathrm{J}$ Immunol. 2003; 170(1):270-278.

30. Rosenthal I. Phthalocyanines as Photodynamic Sensitizers. Photochem Photobiol. 1991; 53(6):859-\&.

31. Wilson AC, Malham GM, Thomsen RJ, Harvey JD and Baguley BC. Determination of the activation spectrum of aluminium phthalocyanine chloride against cultured meningioma cells using a tunable laser. J Clin Neurosci. 1996; 3(3):252-256.

32. Kyriazi M, Alexandratou E, Yova D, Rallis M and Trebst $\mathrm{T}$. Topical photodynamic therapy of murine non-melanoma skin carcinomas with aluminum phthalocyanine chloride and a diode laser: pharmacokinetics, tumor response and cosmetic outcomes. Photodermatol Photoimmunol Photomed. 2008; 24(2):87-94.

33. Stylli SS, Hill JS, Sawyer WH and Kaye AH. Aluminum Phthalocyanine Mediated Photodynamic Therapy in Experimental Malignant Glioma. J Clin Neurosci. 1995; 2(2):146-151.

34. Sekkat N, van den Bergh $\mathrm{H}$, Nyokong $\mathrm{T}$ and Lange N. Like a Bolt from the Blue: Phthalocyanines in Biomedical Optics. Molecules. 2012; 17(1):98-144. 
35. Longo JPF, Lozzi SP, Simioni AR, Morais PC, Tedesco AC and Azevedo RB. Photodynamic therapy with aluminumchloro-phtalocyanine induces necrosis and vascular damage in mice tongue tumors. J Photoch Photobio B. 2009; 94(2):143-146.

36. Grynkiewicz G, Poenie M and Tsien RY. A new generation of $\mathrm{Ca} 2+$ indicators with greatly improved fluorescence properties. The Journal of biological chemistry. 1985; 260(6):3440-3450.

37. Lim MH, Xu D and Lippard SJ. Visualization of nitric oxide in living cells by a copper-based fluorescent probe. Nat Chem Biol. 2006; 2(7):375-380.

38. Lim MH, Wong BA, Pitcock WH, Jr., Mokshagundam D, Baik MH and Lippard SJ. Direct nitric oxide detection in aqueous solution by copper(II) fluorescein complexes. Journal of the American Chemical Society. 2006; 128(44):14364-14373.

39. Makale M. Intravital imaging and cell invasion. Methods Enzymol. 2007; 426:375-401.

40. Leybaert L and Sanderson MJ. Intercellular Ca2+ waves: mechanisms and function. Physiological reviews. 2012; 92(3):1359-1392.

41. Azzam EI, de Toledo SM and Little JB. Direct evidence for the participation of gap junction-mediated intercellular communication in the transmission of damage signals from alpha -particle irradiated to nonirradiated cells. Proceedings of the National Academy of Sciences of the United States of America. 2001; 98(2):473-478.

42. Frank DK, Szymkowiak B, Josifovska-Chopra O, Nakashima T and Kinnally KW. Single-cell microinjection of cytochrome c can result in gap junction-mediated apoptotic cell death of bystander cells in head and neck cancer. Head Neck. 2005; 27(9):794-800.

43. Harada K, Nonaka T, Hamada N, Sakurai H, Hasegawa M, Funayama T, Kakizaki T, Kobayashi Y and Nakano T. Heavy-ion-induced bystander killing of human lung cancer cells: role of gap junctional intercellular communication. Cancer Sci. 2009; 100(4):684-688.

44. Mancuso M, Pasquali E, Giardullo P, Leonardi S, Tanori M, Di Majo V, Pazzaglia S and Saran A. The Radiation Bystander Effect and its Potential Implications for Human Health. Curr Mol Med. 2012.

45. Mancuso M, Pasquali E, Leonardi S, Rebessi S, Tanori M, Giardullo P, Borra F, Pazzaglia S, Naus CC, Di Majo V and Saran A. Role of connexin43 and ATP in long-range bystander radiation damage and oncogenesis in vivo. Oncogene. 2011; 30(45):4601-4608.

46. Mancuso M, Pasquali E, Leonardi S, Tanori M, Rebessi S, Di Majo V, Pazzaglia S, Toni MP, Pimpinella M, Covelli $\mathrm{V}$ and Saran A. Oncogenic bystander radiation effects in Patched heterozygous mouse cerebellum. Proceedings of the National Academy of Sciences of the United States of America. 2008; 105(34):12445-12450.

47. Ceriani F and Mammano F. A rapid and sensitive assay of intercellular coupling by voltage imaging of gap junction networks. Cell communication and signaling : CCS. 2013; 11(1):78.

48. Miller EW, Lin JY, Frady EP, Steinbach PA, Kristan WB, Jr. and Tsien RY. Optically monitoring voltage in neurons by photo-induced electron transfer through molecular wires. Proceedings of the National Academy of Sciences of the United States of America. 2012; 109(6):2114-2119.

49. Verselis VK and Srinivas M. Connexin channel modulators and their mechanisms of action. Neuropharmacology. 2013.

50. Ozawa H, Matsunaga T, Kamiya K, Tokumaru Y, Fujii M, Tomita $\mathrm{T}$ and Ogawa K. Decreased expression of connexin-30 and aberrant expression of connexin-26 in human head and neck cancer. Anticancer research. 2007; 27(4B):2189-2195.

51. Sirnes S, Bruun J, Kolberg M, Kjenseth A, Lind GE, Svindland A, Brech A, Nesbakken A, Lothe RA, Leithe E and Rivedal E. Connexin43 acts as a colorectal cancer tumor suppressor and predicts disease outcome. International journal of cancer Journal international du cancer. 2012; 131(3):570-581.

52. Teleki I, Krenacs T, Szasz MA, Kulka J, Wichmann B, Leo C, Papassotiropoulos B, Riemenschnitter C, Moch H and Varga $Z$. The potential prognostic value of connexin 26 and 46 expression in neoadjuvant-treated breast cancer. BMC cancer. 2013; 13:50.

53. Goeger DE, Riley RT, Dorner JW and Cole RJ. Cyclopiazonic acid inhibition of the Ca2+-transport ATPase in rat skeletal muscle sarcoplasmic reticulum vesicles. Biochemical pharmacology. 1988; 37(5):978-981.

54. Maruyama T, Kanaji T, Nakade S, Kanno T and Mikoshiba K. 2APB, 2-aminoethoxydiphenyl borate, a membranepenetrable modulator of $\operatorname{Ins}(1,4,5) \mathrm{P}-3$-induced $\mathrm{Ca} 2+$ release. J Biochem-Tokyo. 1997; 122(3):498-505.

55. Dunn PM and Blakeley AGH. Suramin - a Reversible P2Purinoceptor Antagonist in the Mouse Vasdeferens. British journal of pharmacology. 1988; 93(2):243-245.

56. Mccall TB, Feelisch M, Palmer RMJ and Moncada $\mathrm{S}$. Identification of N-Iminoethyl-L-Ornithine as an Irreversible Inhibitor of Nitric-Oxide Synthase in Phagocytic-Cells. British journal of pharmacology. 1991; 102(1):234-238.

57. Kim YE, Chen J, Langen R and Chan JR. Monitoring apoptosis and neuronal degeneration by real-time detection of phosphatidylserine externalization using a polaritysensitive indicator of viability and apoptosis. Nature protocols. 2010; 5(8):1396-1405.

58. Silva VH, Martins MP, de Oliveira HC and Camargo AJ. Theoretical investigation of nitric oxide interaction with aluminum phthalocyanine. Journal of molecular graphics \& modelling. 2011; 29(6):777-783.

59. Carneiro ZA, de Moraes JCB, Rodrigues FP, de Lima RG, Curti C, da Rocha ZN, Paulo M, Bendhack LM, Tedesco AC, Formiga ALB and da Silva RS. Photocytotoxic activity 
of a nitrosyl phthalocyanine ruthenium complex - A system capable of producing nitric oxide and singlet oxygen. J Inorg Biochem. 2011; 105(8):1035-1043.

60. Ramos LC, dos Santos JS, Costa MS, da Silva RS, do Nascimento FB and Ribeiro AO. Photocytotoxicity evaluation of ruthenium-phthalocyanines as nitric oxide and singlet oxygen producers in cancer cell lines. J Biol Inorg Chem. 2014; 19:S675-S675.

61. Hidalgo C and Donoso P. Crosstalk between calcium and redox signaling: from molecular mechanisms to health implications. Antioxidants \& redox signaling. 2008; 10(7):1275-1312.

62. Feissner RF, Skalska J, Gaum WE and Sheu SS. Crosstalk signaling between mitochondrial $\mathrm{Ca} 2+$ and ROS. Front Biosci (Landmark Ed). 2009; 14:1197-1218.

63. Figueroa XF, Lillo MA, Gaete PS, Riquelme MA and Saez JC. Diffusion of nitric oxide across cell membranes of the vascular wall requires specific connexin-based channels. Neuropharmacology. 2013; 75:471-478.

64. Decrock E, Krysko DV, Vinken M, Kaczmarek A, Crispino G, Bol M, Wang N, De Bock M, De Vuyst E, Naus CC, Rogiers V, Vandenabeele P, Erneux C, Mammano F, Bultynck G and Leybaert L. Transfer of IP(3) through gap junctions is critical, but not sufficient, for the spread of apoptosis. Cell death and differentiation. 2012; 19(6):947957.

65. Decrock E, De Bock M, Wang N, Gadicherla AK, Bol M, Delvaeye T, Vandenabeele P, Vinken M, Bultynck G, Krysko DV and Leybaert L. IP3, a small molecule with a powerful message. Bba-Mol Cell Res. 2013; 1833(7):17721786.

66. Bai D, del Corsso C, Srinivas $M$ and Spray DC. Block of specific gap junction channel subtypes by 2-aminoethoxydiphenyl borate (2-APB). The Journal of pharmacology and experimental therapeutics. 2006; 319(3):1452-1458.

67. Cronier L, Crespin S, Strale PO, Defamie N and Mesnil M. Gap Junctions and Cancer: New Functions for an Old Story. Antioxidants \& redox signaling. 2009; 11(2):323-338.

68. Naus CC and Laird DW. Implications and challenges of connexin connections to cancer. Nat Rev Cancer. 2010; 10(6):435-441.

69. Di Virgilio F, Fasolato C and Steinberg TH. Inhibitors of membrane transport system for organic anions block fura2 excretion from PC12 and N2A cells. The Biochemical journal. 1988; 256(3):959-963.

70. Joblove GH and Greenberg D. (1978). Color spaces for computer graphics. Proceedings of the 5th annual conference on Computer graphics and interactive techniques: ACM), pp. 20-25.

71. Crank J. (1975). The Mathematics of Diffusion. (London: Oxford University Press). 